\title{
Stage I Uterine Sarcoma AJCC v7
}

National Cancer Institute

\section{Source}

National Cancer Institute. Stage I Uterine Sarcoma A/CC v7. NCI Thesaurus. Code C8258.

Stage I includes: T1, N0, M0. T1: Tumor limited to the uterus. N0: No regional lymph node metastasis. M0: No distant metastasis. This staging applies to leiomyosarcoma, endometrial stromal sarcoma, and adenosarcoma. (AJCC 7th ed.) 